\title{
A Study on the "Going out" Paths of Tourism Industry of TCM Health Preservation Culture Driven by One Belt, One Road
}

\author{
Qianqian Qu
}

\author{
School of Foreign Languages, Shaanxi University of Chinese Medicine, Xianyang, Shaanxi 712046, \\ China \\ megan8111@163.com
}

\begin{abstract}
Keywords: "One Belt and One Road" Initiative; "Going Out"; Tourism Industry; TCM Health Preservation Culture
\end{abstract}

\begin{abstract}
This article first reviewed the history and present situation of TCM health preservation culture in Shaanxi province, and analyzed several problems that Shaanxi tourism industry of TCM preservation health culture faces. Based on these problems, the author put forward "going out" paths of Shaanxi tourism industry of TCM preservation health culture. The purpose of this paper aims to make some explorations for the development of tourism industry of TCM health preservation culture in tourism 4.0 era driven by One Belt, One Road initiative.
\end{abstract}

\section{Introduction}

Traditional Chinese culture has exerted a profound influence on the formation and development of traditional Chinese medicine. TCM health preservation culture emphasizes the harmony and unity between human beings and nature, with the core value of "people-oriented" and "Perfect skill and sincerity of great doctors", reflecting the Chinese cultural values, ecological and cultural values. It is the treasure of ancient Chinese science, and the key to the treasure-house of Chinese civilization ${ }^{[1]}$. Zhang Boli, an academician of the Chinese academy of engineering, said that Chinese medicine culture is an integral part of traditional Chinese culture and a representative of China's soft power. The philosophy and history of TCM represent the essence of Chinese culture. Blindly advocating western medicine and neglecting the inheritance and development of TCM will have no help to the well-being of the whole world ${ }^{[2]}$.

Since ancient times, China has had the long history of TCM cross-cultural communications along the route of the ancient Silk Road, for example, there are quite a few such records in Southern Golden Prescriptions, and Medical Secretes of an Official ${ }^{[3]}$. In the central plains, Chinese herbal medicine was transported to the western countries through the silk road, and the vast majority of Chinese herbal medicine was originated from the great Qinling mountains located in Shaanxi province. How to spead TCM and its culture from Shaanxi to the nationwide and worldwide requires effective communication paths. In September and October 2013, Chinese President Xi Jinping proposed the initiative of building the "new silk road economic belt" and "the 21 st century maritime silk road" which provides effective paths. Shaanxi provincial government put forward TCM development strategic planning (2017-2030): to promote TCM's effective integration with tourism industry, namely, to develop the traditional Chinese medicine and health rehabilitation, cultural communication, commercial exhibition, Chinese herbal medicine and in the integration of TCM health tourism industry. By 2030, a strong province of traditional Chinese medicine will be established. We will set up 50 demonstration bases for TCM health and rehabilitation, medical care and health tourism. This shows that there is still a long way to go in promoting the development of Shaanxi TCM health preservation industry ${ }^{[4]}$.

\section{Current Situation and The Future Plan}

In recent years, with the health concept and the transformation of medical model, TCM gains increasing recognition among the whole world in prevention and treatment of common diseases, frequently-occurring diseases, chronic diseases.To implement "One Belt, One Road" Initiative, 
increase exchanges and cooperation among the countries all along the route and create a new pattern of TCM all-round opening to the outside world, recently, the state administration of TCM and the national development and reform commission jointly issued the ""One Belt and One Road"TCM development plan (2016-2020) "(hereinafter referred to as the" plan "). The plan covers the basic situation, overall requirements, major tasks and safeguard measures of TCM. According to the plan, by 2020 , on the basis of the surrounding countries and key countries along the route, 30 overseas centers of TCM will be constructed , 20 items of regulations and policies will be issued and 100 kinds of Chinese medicine products will be registered, and more than 50 demonstration bases will be established as well.

Current Condition. At present, TCM has spread to 183 countries and regions, and China has signed 86 cooperation agreements with foreign governments, regional authorities and international organizations. Tu youyou was awarded the 2015 Nobel Prize in physiology of medicine for the discovery of artemisinin, indicating that Chinese medicine has made remarkable contributions to human health. Traditional Chinese acupuncture is listed in UNESCO's representative list of intangible cultural heritage of humanity, and the compendium of Materia medical and the Huangdi inner scriptures are listed in the world memory directory. The international organization for standardization (ISO) has set up the TCM technical committee (ISO/TC249) and has formulated more than 10 international standards on TCM. As a representative of traditional medicine, TCM for the first time is listed on the world health organization's international classification of diseases code (ICD - 11) ${ }^{[5]}$; as an important part of the international medical system,TCM is playing a positive role in promoting human health. According to the report on People's Daily of May 15, 2015, in the future, the export of TCM herbs is expected to be no longer a "grass" for sale, but a "medicine" with high added value.Especially the implementation of the "One Belt and One Road"initiative , among 103 member states along the route approved use of acupuncture and moxibustion, 29 countries set up the laws and regulations of traditional medicine, 18 include acupuncture in medical insurance.TCM has gradually entered the foreign regulatory system and has been registered as medicine in Singapore, Russia, Vietnam, Cuba, the united Arab emirates and other countries.

However, the development of TCM driven by "One Belt, One Road"initiative still faces many difficulties and challenges. Due to differences in cultural background and theoretical system, the health management model along the route is mostly based on the modern medical system, and TCM faces the barriers of policy and technology. Traditional medicine in most countries is in complementary and alternative status. The quality and efficiency of the development of TCM in China is still weak, and the foundation of "going out" needs to be strengthened. At the same time, the existing extroversion cooperation mechanism is also a week one.One of the very realistic reasons for this phenomenon is the shortage of TCM service trade professionals.Many people who are engaged in TCM are highly skilled but have no language foundation. At present, there are few bilingual talents, and even fewer people with both technical and linguistic advantages.

The plan focuses on the "five links" tasks, including policy communication and improving the mechanism of intergovernmental exchanges and cooperations; resource sharing and sharing of TCM services with countries along the routes; strengthening people-to-people and cultural exchanges with countries along the belt and road; Science and technology Unicom and promoting the inheritance and innovation of TCM; unimpeded trades and the development of TCM health services and other aspects. The future plan will focus on strengthening the construction of international medical service system of TCM, international education and cultural communication system of TCM, international science and technology system of TCM, Chinese medicine international trade system construction, etc. 


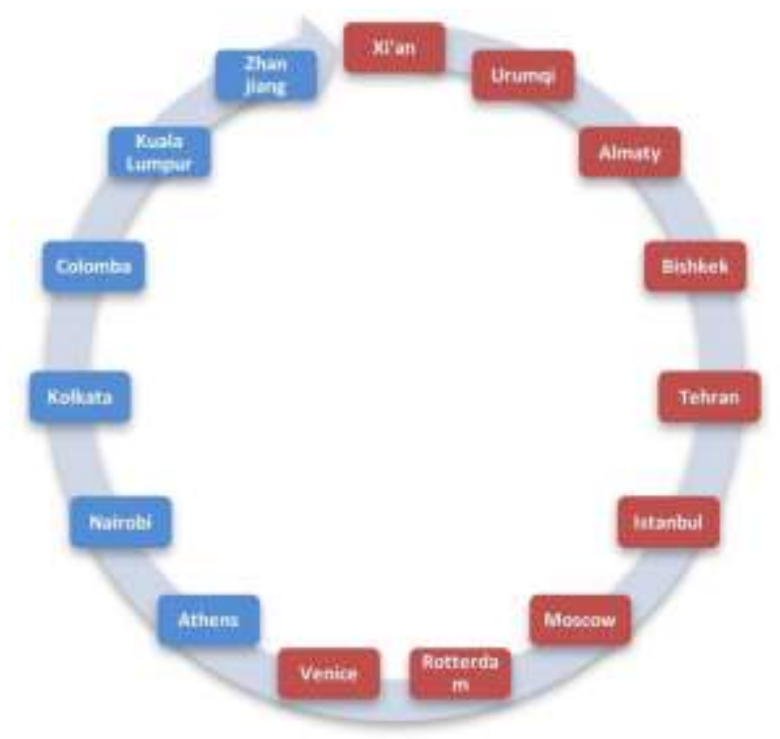

Figure 1. Finite Silk Road Routes (Red: the land route; Blue: the sea route)

Future Plan. In order to ensure the effective implementation of the plan, the plan has been strengthened by improving the policy mechanism, increasing financial and fiscal support, strengthening the construction of talent team and strengthening the implementation of the organization. The establishment of the multi-sectoral coordination mechanism, for example, policies about TCM construction will be implemented from district development into the national one, covering health, science and technology, culture, trade and other development strategies, which may provide a strong policy support along the Silk Road. Along the route, related countrites will promote cooperation in bilateral countries, strengthen relevant laws and regulations, policies and measures in areas such as information exchange, intensify consultations between the government and countries along the route to easy access to services and products of TCM. In terms of strengthening the construction of talents, Shaanxi University of Chinese Medicine bears the responsibilty to cultivate a group of talents with solid basic skills, proficient in using foreign languages and familiar with international rules through a variety of channels. Besides, introducing more overseas talents, for an instance, those experts who are proficient in international exchanges and cooperation, etc.

Generally speaking, qualified TCM cross-cultural communicators require at least the following three abilities: familiar with the culture of TCM knowledge, more skilled bilingual or multilingual skills, strong consciousness of Chinese culture.According to the statistics of the questionnaires and feedbacks during summer vacation in 2017 , the author drew the conclusions that most Chinese studentsthe had the first ability, but at the same time, those who possess the second and the third ability are scarce;For teachers in Chinese medicine universities, the ratio of teachers with the first and third abilities is large while the number of teachers with the second ability is relatively small.For overseas students in Chinese medicine universities, their first and third abilities are much weaker than those of domestic students, and their second abilities are relatively strong. Hence, it is quite obvious that the measures we should take to enhance the abilites for these three categories who plays a very important role in TCM cross-cultural communication. Thus, the focus should be on cultivating high quality faculties and students' bilingual ability, improve the teachers and the students' ability of intercultural communication and translation ability.For overseas students who come to Chinese medicine colleges and universities, the priority thing is to strengthen their knowledge of Chinese medicine, and cultivate their cultural consciousness of loving Chinese medicine and being committed to spreading the culture of Chinese medicine. 


\section{"Going Out "Paths of TCM Health Preservation Culture}

Ancient ChangAn (the president Xi'an) has its unique geographical advantages and rich historical and cultural background which was once the starting point of the ancient Silk Road from the Han Dynasty $^{[6]}$. Today Xi'an restarts as the new starting point for both boosting the economy and the spread of TCM culture. Relying on Qinling mountains as well as many famous medical experts such as Sun Simiao, whose hometown was located at the present Tongchuan City, it is quite effective to merge tourism industry with TCM to create new industry, and finally realizes the development of economy and culture in parallel and a win-win situation.

"Internet + TCM" in Tourism 4.0 Era. In tourism 4.0 era, TCM tourism industry is essentially integrated into the Internet.With the continuous development and innovation of APP in cellphone, customized tourism and personalized tourism are more and more popular among the masses. With the help of specific APP, functions such as telemedicine, mobile medical treatment and real-time download of electronic prescriptions can also be realized, which is the most prominent features different from the previous era in tourism 4.0 era. In addition, people pay highly attention to health, hence through customized and personalized health tourism plans, it is easy for users to form the integration of medical information services, such as visit to health preservation cultural bases, online purchase of health preservation products, convenient access to electronic prescriptions and so on.

It is no doubt that Internet plays a key role in current era, hence the construction of Chinese medicine network information platform needs to follow up quickly as well as the related web softwares also need to accelerate the development.The author looked up to the relevant official accounts with the key word "Yaowang mountain"and found that the service recommendation of the scenic area needed to be further added. The official account "Qianjin pharmacy bureau and famous doctor house in Yaowang mountain" currently only delivered 19 pieces of news, meanwhile there is no product buying online service nor online consulting services. In contrast, the public account "qinling taibaishan pharmaceutical king tea" has "online consultation" and "product introduction" columns, but no online-purchase service. All these indicate that the Internet construction of Sun Simiao TCM health preservation culture is not enough, and there is no one-stop service for publicity and purchasing. In brief, it is quite essential to accelerate the TCM APP or other Internet platform construction in order to successfully spread "TCM stories" abroad.

TCM Cultural Commucnication Via TCM Cultural Bases. Take Sun Simiao memorial hall in Tongchuan City in Shaanxi and the museum of Shaanxi University of Chinese Medicine for example.Sun Simiao memorial is an important exhibition base to show the cultural heritage of traditional Chinese medicine. The memorial hall is divided into main five areas named by TCM terms, that is, Qi Huang, Yin and Yang, homology, Xing Lin and Wu Xing(five elements) and demonstrate extensive and profound TCM cultrue from various angles. Specificially, there sets up a specific zone for display of TCM health preservation culture-- derivatives exhibition area.Attracting tourists from both home and abroad to visit here will undoubtedly enable tourists to enjoy their travel and vacation, and meanwhile fully experience the magic of TCM culture. The unique museum of Shaanxi University of Chinese Medicine is the earliest independent medical history museum among China's medical colleges and universities. There are four cultural display series, including "ancient doctors in Shaanxi province", "Shaanxi famous ancient pharmacy", "national minority medicine (Tibetan medicine and Mongolian medicine, etc.)", "Chinese and foreign medicine exchanges", "ancient city sanitation", " medicine and health care in Yan'an" and other 14 projects.The collection is rich in historical relics and has a high academic level, playing an important role in teaching, scientific research, TCM cross-cultural communication, patriotism education and popularization of science among primary and middle school students.

If possible, it is a good approach to estabish a brand enterprise of TCM culture industry together with some other successful enterprises in Shaanxi province, and encourage Chinese and foreign tourists to visit Chinese medicine enterprises ${ }^{[7]}$. Xianyang 505 Shenqi belt is a successful example of TCM health care brand. As an old Chinese saying goes, "Seeing is believing". There is no doubt 
that to start TCM enterprises and clinics at abroad is a good way to spread TCM culture ; meanwhile, the author proposes to attract tourists to visit Chinese local pharmaceutical factories and tourist basis of TCM production processes from the raw materials to the granules, from the accurate detection to the sealing plastic packaging, for example, the production of the Pudilan Granule, which is so standardized and rigorous in the Affiliated Hospital of Shaanxi University of Chinese Medicine.

Cultivation of TCM Inter-disciplinary Talents. In Shaanxi Tongchuan city, Yaowang Mountain and Yaowang Temple are famous TCM cultural attractions, but the local people do not think highly of local TCM doctors. This shows that introduction of high level talents of traditional Chinese medicine is the key factor to the development of the local Chinese medicine ${ }^{[8]}$.In recent years, many international students along the route of "one belt, one road" choose Shaanxi university of Chinese Medicine as their ideal places to study Chinese traditional culture, traditional Chinese medicine acupuncture and moxibustion, massage and other traditional Chinese medicine treatment programs. After graduation, many of them make use of their language advantage and apply the technology of traditional Chinese medicine constantly in their own country in many ways, continuously spreading TCM culture all over the world. Some special courses are proposed to set up, such as " TCM health preservation and marketing", "TCM health preservation and cross-cultrual communication", "TCM culture and tourism management",etc. in order to speed up the effective integration between disciplines, training TCM inter-disciplinary talents.

TCM Translation Strategy. It is vital to pay attention to language translation strategies in order to enable the characteristics of TCM health tourism to play a substantial role for international tourists and achieve the purpose of spreading TCM culture. TCM cultural tourism translation does not need to include too many esoteric theories and terminology of TCM, which mainly focus on the usage and effect of Chinese herbs and even some mystery legends. The mode of translation should give full consideration to the psychological and cultural reception of tourists. The choice of language and content should serve the purpose of cultural communication and tourism industry. Ge believes that the international spread of TCM should emphasize on the promotion of "purpose translation": it is aimed at the audience and focuses on the effect. "Target audience" is a term for translators to integrate the international acceptance of TCM output into translation thinking, and fully consider the understanding and digestion of TCM culture by ordinary audiences. The emphasis on "purpose translation" is to emphasize the culture reception.

\section{Conclusion}

TCM health cultural tourism is a new kind of tourism industry under the development of diversified tourism, which promotes the dissemination of traditional Chinese Medicine culture and the tourism economy. Relying on the great Qinling mountains, Shaanxi province possesses a very rich cultural tourism resources, and has the unique geographical advantage of developing TCM culture tourism. It is the high time to promote the development of cultural tourism industry of TCM as well as a realistic choice to spread TCM culture and promote economic and social development of Shaanxi province.

\section{Acknowledgment}

This paper is supported by the subproject of research project of Shaanxi Administration of Traditional Chinese Medicine (Shaanxi TCM Culture Study: Academic Development Study on Chang'an Medical Schools, No. ZCMS007).

\section{References}

[1] Croizier, R. C. (1968). Traditional Medicine in Modern China: Science, Nationalism, and the Tensions of Cultural Change(No. Ser-34). HARVARD UNIV CAMBRIDGE MA EAST ASIAN RESEARCH CENTER. 
[2] Yu, H. (2017). Motivation behind China's 'One Belt, One Road'initiatives and establishment of the Asian infrastructure investment bank. Journal of Contemporary China, 26(105), 353-368.

[3] Liang Zhongxiao (2014).Qinling Culture in Han Dynasty. Journal of Xianyang Normal University, l(1), 16-24.

[4] Shaanxi Provincial Document (2017).TCM Development in Shaanxi Province (2017-2030. Zheng Fu Gong Bao, 12(1), 13-18.

[5] Ferdinand, P. (2016). Westward ho-the China dream and 'one belt, one road': Chinese foreign policy under Xi Jinping. International Affairs, 92(4), 941-957.

[6] Swaine, M. D. (2015). Chinese views and commentary on the 'One Belt, One Road'initiative. China Leadership Monitor, 47(2), 3.

[7] Yu, F., Takahashi, T., Moriya, J., Kawaura, K., Yamakawa, J., Kusaka, K., ... \& Kanda, T. (2006). Traditional Chinese medicine and Kampo: a review from the distant past for the future. Journal of International Medical Research, 34(3), 231-239.

[8] Xiong Min (2017). Analysis of the Development of TCM in Midwest Areas in China . Jian Kang Zhi Lu( Road to Health), 10(16), 205. 